\title{
UROLITHIASIS IN CHILDHOOD
}

\author{
BY \\ N. A. A. MYERS \\ From The Hospital for Sick Children, Great Ormond Street, London
}

(RECEIVED FOR PUBLICATION, DECEMBER 14, 1956)

During the nineteenth and earlier centuries urolithiasis was a common paediatric problem and the many reports in the literature bear testimony to this. The total incidence of stone in the urinary tract has lessened in this country and at the same time there has been a disproportionate decrease in the number of cases seen in children so that the present incidence in childhood is low. However, urolithiasis must still be regarded as a problem with some paediatric significance, although, apart from relevant sections in special text-books, the recent literature on this subject has been limited to isolated accounts of individual cases. In order to obtain some idea of the present incidence of the disease a review of the clinical material of The Hospital for Sick Children was undertaken. At the present time stone in children not only differs in its incidence from that in the older reports but also in its character. Previously the condition was endemic and there were wellknown 'stone-districts', such as Norfolk. Calculi were then predominantly found in the bladder and they were mostly composed of uric acid or urates. Not only are stones no longer endemic but those stones which do occur tend to be of different site and composition. It is also of interest to note that there does appear to be a difference in the nature of stone as it is seen in different localities. Thus in the nonendemic series reported by Winkel-Smith in 1944 a high percentage of stones was composed of calcium oxalate whereas in Meredith Campbell's cases the majority were composed of uric acid and urates. Stones are still common in many parts of the world and there the triad of endemicity, lower urinary tract calculi and stones composed of uric acid or urates still occurs.

During the past 20 years 85 children with urolithiasis were admitted to The Hospital for Sick Children, Great Ormond Street. There was no evidence to suggest that the stones were in any way endemic and they also conformed in other respects to recent reports in that the incidence was considerably higher in the upper than in the lower part of the urinary tract. Analysis of the stones revealed a high proportion of phosphatic calculi so that this series differs from both of those quoted above as well as differing in many respects from earlier reports. The comments which follow are based on the experience of these 85 patients who were all in-patients at some stage during the years 1936 to 1956 . During the latter half of this period the total number of admissions to the hospital was 67,127 and during this 10 years 63 of the cases presented. The present relative incidence at The Hospital for Sick Children is thus approximately one case per 1,000 admissions, and, as world affairs considerably modified the figures for admissions during the first half of the period under review, the latter 10 years are more likely to be of present-day significance.

\section{Classification}

Although various methods of classification are available, including, for example, the anatomical situation of the stone, the age incidence, or the sex incidence, it would be preferable if all cases could be classified along aetiological lines. Unfortunately this is not yet possible and therefore it is probably better to recognize various clinical groups. To this end the 85 cases have been sub-divided into the following four groups:-

Group 1. Calculi occurring in the urinary tract in which there is an underlying congenital anomaly: there are 25 cases in this group and although it cannot be claimed that the congenital anomaly is the sole factor in these cases it seems reasonable to believe that it is the most significant in the production of the calculi.

Group 2. Calculi occurring in patients with errors of metabolism: there were nine such cases.

Group 3. Calculi resulting from other recognizable causes, of which there were five cases.

Group 4. Calculi due to unknown causes numbered 46 cases. 
Table 1 summarizes this classification and also indicates the further nature of many of the cases and the sex incidence.

TABLE 1

CLASSIFICATION OF 85 CASES OF UROLITHIASIS IN CHILDHOOD

\begin{tabular}{|c|c|c|c|}
\hline Group and Classification & No. of Cases & Males & Females \\
\hline $\begin{array}{l}\text { 1.5Congenital } \\
\text { Mega-ureter } \\
\text { Hydronephrosis } \\
\text { Ectopia vesicae and } \\
\text { epispadias } \\
\text { Calyceal diverticulum } \\
\text { Crossed ectopia } \\
\text { Pyelon duplex } \\
\text { 2. Metabolic } \\
\text { Cystinuria } \\
\text { Oxaluria } \\
\text { 3. Other recognizable causes } \\
\text { Neurogenic bladder } \\
\text { Nephrocalcinosis } \\
\text { Recumbency } \\
\text { Foreign body } \\
\text { 4. Unknown }\end{array}$ & $\begin{array}{r}25 \\
10 \\
5 \\
7 \\
1 \\
1 \\
1 \\
9 \\
5 \\
4 \\
5 \\
2 \\
1 \\
1 \\
1 \\
46\end{array}$ & $\begin{array}{r}17 \\
6 \\
4 \\
5 \\
1 \\
1 \\
5 \\
4 \\
1 \\
3 \\
1 \\
1 \\
1 \\
27\end{array}$ & $\begin{array}{r}8 \\
4 \\
1 \\
2 \\
- \\
1 \\
4 \\
1 \\
3 \\
2 \\
2 \\
- \\
19\end{array}$ \\
\hline Total & 85 & 52 & 33 \\
\hline
\end{tabular}

\section{Clinico-pathological Features}

Stone in the urinary tract may be symptomless, in which case its presence is only detected at operation,

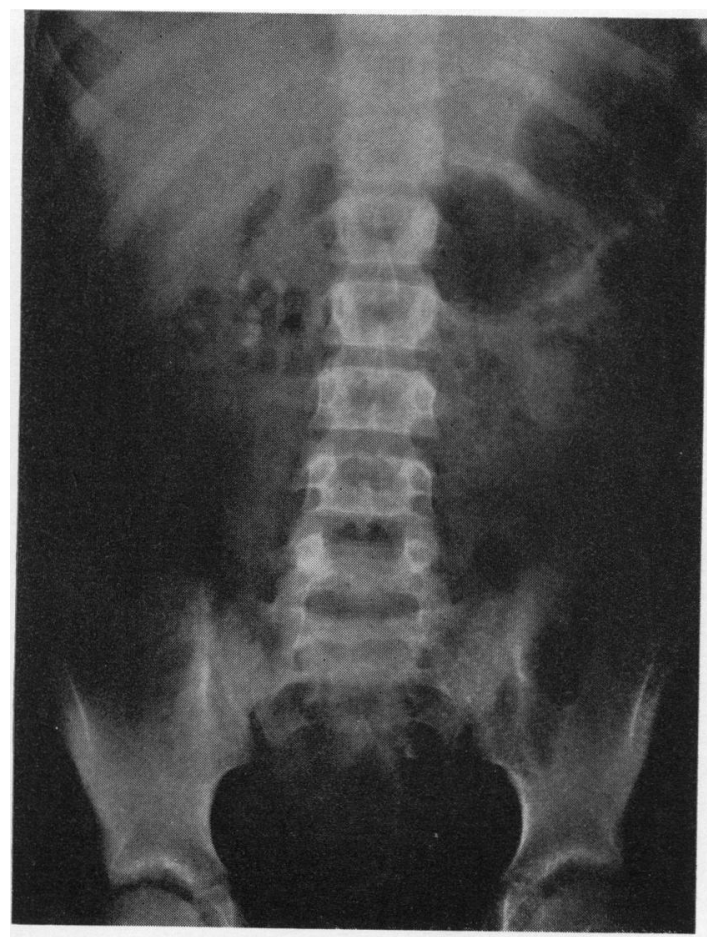

1 a

FIG. 1.-Renal calculi in congenital hydronephrosis: plain radiographs and intravenous pyelogram. These calculi were symptomless and were incidentally discovered during the course of an investigation of splenomegaly.

by incidental investigation, or at necropsy. Most cases do have symptoms, pain and haematuria being most frequently observed, but in addition to the passage of stones, the symptoms of infection and nonspecific complaints are not uncommon. The children in this series had diverse clinical features and these were studied in each of the groups mentioned above, and at the same time the possible aetiological factors were considered in each case.

Group 1. Of the 25 cases which occurred in children with underlying congenital urinary abnormalities, five were associated with hydronephrosis. The symptomatology of this group was rather diverse but all the cases had in common a degree of pelvi-ureteric obstruction which would certainly have prevented the passage of the stones. Three of these cases were uninfected and one was completely symptomless, the stones being discovered in the course of investigation of splenomegaly (Fig. 1). In this, and in two of the other cases, the hydronephrosis was bilateral whereas the calculi were unilateral. In the four symptomatic cases the presenting complaints were abdominal pain in one, abnormal urine in the second, haematuria in the

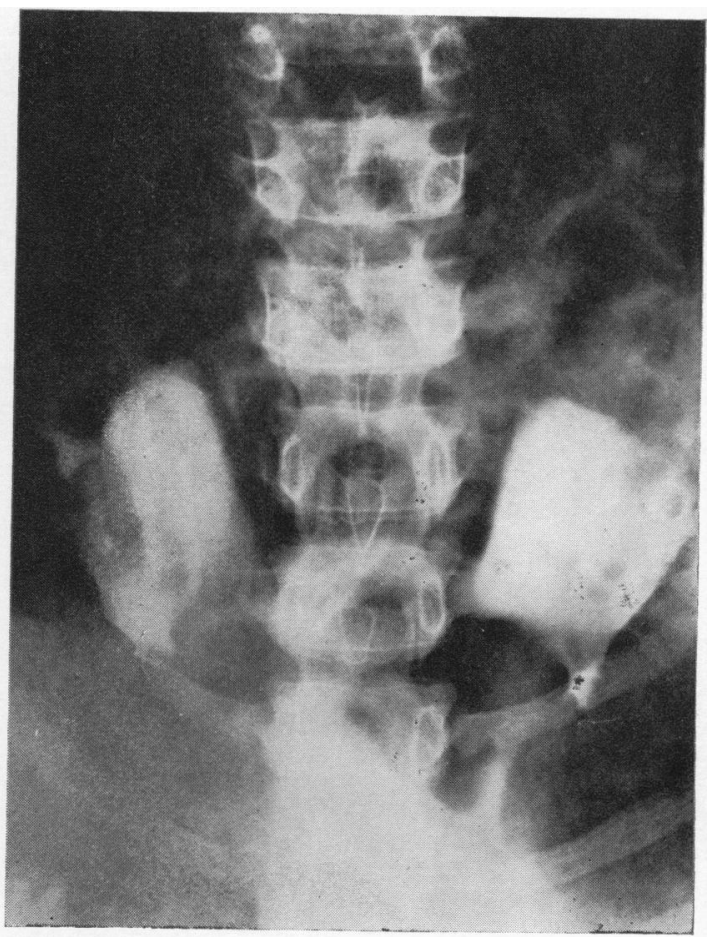

$1 \mathrm{~b}$ incidentally discovered during the course of an investigation of splenomegaly. 
third and symptoms of infection in the fourth, symptoms which can readily be attributed to hydronephrosis and not necessarily to stone.

In 10 of the cases the condition of mega-ureter was present. In three of these, there was stenosis of the lower end of the ureter, but in the others there was no such narrowing nor was there any evidence of extrinsic ureteral obstruction or infra-vesical obstruction. Even if one refers to the first three cases as examples of hydro-ureters, the remaining seven are best classified under the heading of megaureter. This group does not include any cases in which the ureteric dilatation was secondary to stone impaction or took the form of ureterectasis below pelvic or renal stones. In many of these cases the symptoms were those which might just as easily have occurred in similar cases uncomplicated by stones, although in three of the cases stones were passed spontaneously. Infection was present in eight of the 10 cases and there was a relatively high recurrence rate (four cases). At operation many of the calculi were very mobile and this, together with the multiplicity of the stones (Fig. 2) and the unspecific nature

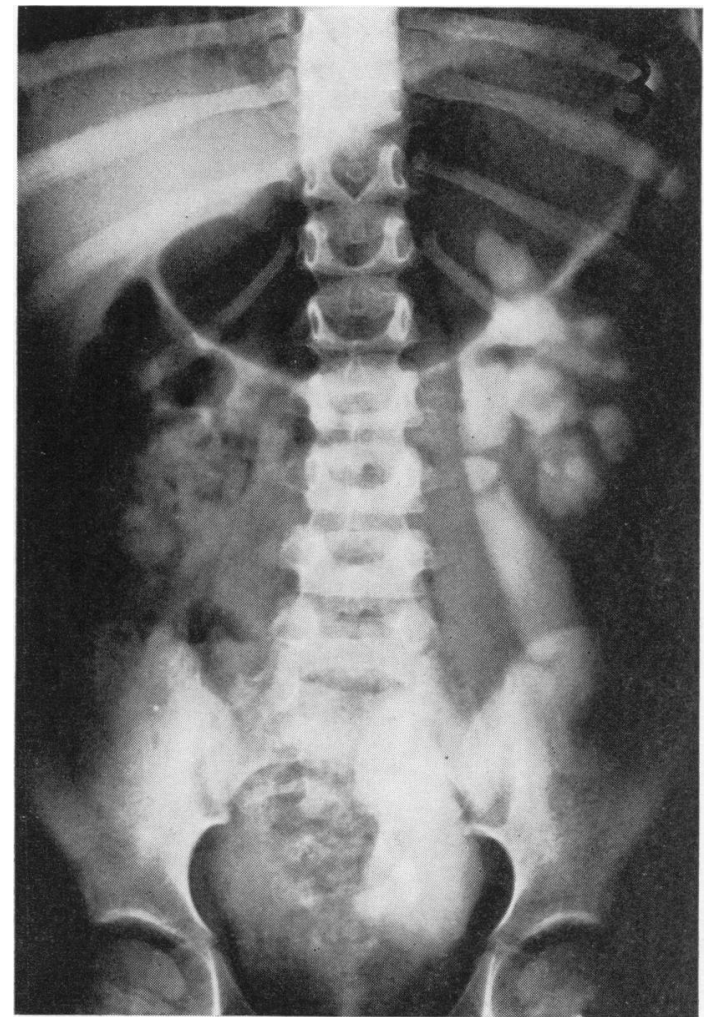

FIG. 2.-Multiple calculi in congenital mega-ureter: intravenous pyelogram in a girl who presented when aged 3 years with a history of cloudy urine.

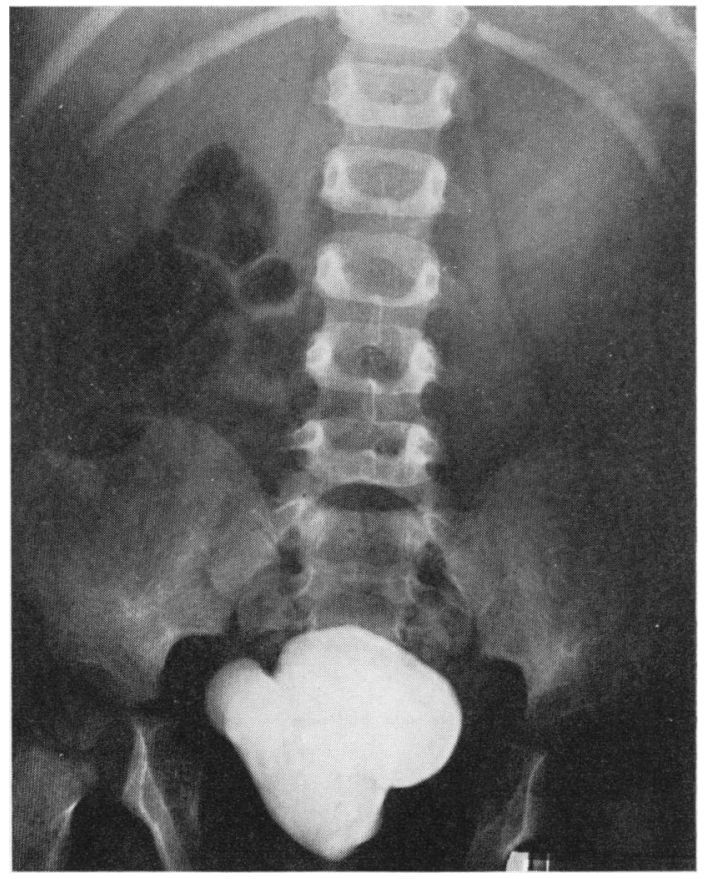

FIG. 3.-Vesical calculi in ectopia vesicae: straight radiograph showing stones in the reconstructed bladder. Symptoms included pain and attacks of straining.

of the symptoms, can be regarded as the main features of this particular group.

Three of the 'congenital' cases require but little mention. One case was associated with a calyceal diverticulum and this presented with the symptoms of infection. In the single case associated with a pyelon duplex there was persistent albuminuria while in the child with crossed ectopia haematuria was the initial complaint.

This leaves seven cases which were included in the first group. These seven were present in association with ectopia vesicae or epispadias and they therefore form a rather different group. This applies particularly to six of the cases in which the stones were found in the bladder or urethra following reconstructive surgery (Fig. 3). This group of cases is responsible for the highest percentage of vesical calculi in the entire series. This is certainly in marked contrast to the state of affairs in those series, both present and past, which are endemic in character. Pain and symptoms of infection were predominant in the six cases, although infection was not universal within the group. In four of these six cases with reconstructed lower urinary tracts, stones recurred, sometimes in the bladder, sometimes in the urethra and in one case a stone formed in the vagina. 
In the seventh case in this group, a renal calculus followed the operation of uretero-colostomy.

With regard to the 'congenital' group as a whole, infection and stasis, separately or together, are the most significant factors in the pathogenesis of stone. This certainly applies to the cases with hydronephrosis, with congenital ureteric dilatation, and in this series to the case with a calyceal diverticulum and probably to the case with crossed ectopia. It is not possible to be certain about the case associated with pyelon duplex, although there, too, stasis may well have been a causal factor. In the reconstructed bladder, abnormal detrussor activity is likely to be a potent cause of urinary stasis.

Group 2. In nine of the series, an error of metabolism was detected, five of these being children with cystinuria and four were cases of familial oxaluria. The most obvious feature in this group was the absence of infection; in eight of the nine cases, the urine was sterile. Other features which were rather typical of this group included the presence of stones in the lower urinary tract (in four of the cases, two with vesical and two with urethral stones) and the

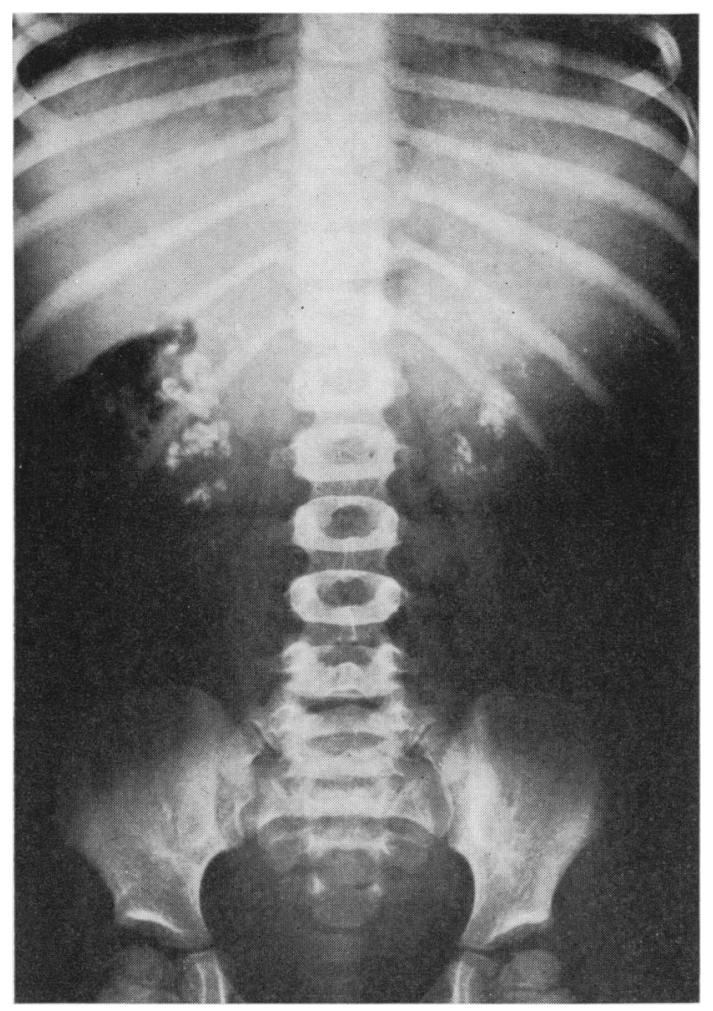

FIG. 4.-Familial oxaluria with nephrocalcinosis: plain radiograph of the abdomen in a child aged 2 years who had passed calcium oxalate stones in the urine five months' previously. fact that the stones were for the most part small. Their site and character tend to lead to the spontaneous passage of metabolic stones and this was described in two of the cases. Four of the cases had haematuria amongst their symptoms and in two of these this was the presenting complaint. There was a positive family history in three of the five cystinurics and all four oxalurics.

Familial oxaluria is a much less common condition than cystinuria and may be associated with diffuse renal calcification or calculus formation or both. Three of the cases in this series occurred in twin girls and their sibling brother. In one twin and the brother, haematuria was the presenting symptom, while the other twin was symptomless. The fourth case had a sibling with calculi and in addition had radiological evidence of nephrocalcinosis (Fig. 4). In this case, the oxalate excretion was demonstrated to be excessive. These cases of familial oxaluria are comparable to those reported by various writers, e.g., Aponte and Fetter (1954).

Group 3. These cases were grouped together for reasons of convenience and their clinical features are in no way remarkable. There was only one recumbency calculus in the series and this occurred in a boy with severe osteomyelitis. Haematuria was his presenting symptom. One patient had a foreign body calculus; the broken-off tip of a polythene catheter which had been previously inserted in the course of an operation on the rectum being the nidus. Incidentally, it is a little surprising that in the series there was no example of the not uncommon type of case, namely the girl with a vesical calculus surrounding a hair clip. Neurogenic disorders of the bladder were responsible for two of the cases; in one the calculus was found in the ureter, in the other in the kidney. The latter of these two ultimately died. The fifth case in this group was a baby with nephrocalcinosis; this diagnosis was made when the baby was aged 5 months, and seven months later calculi made their appearance in the left kidney and bladder.

The miscellaneous cases were really grouped together because the aetiological factors concerned were reasonably definite, but at the same time it was not possible to classify them with any of the other groups. In neurogenic disorders of the bladder, infection and stasis can be regarded as causal and similar factors can justifiably be invoked in the boy with osteomyelitis and recumbency calculi. The foreign body calculus does not present any real problem. The fifth member of this group is the case with nephro-calcinosis. Of the various causes of this condition, it seemed that infantile renal acidosis was the most likely basis in this case. This disease and allied metabolic disorders associated with 
nephro-calcinosis are not uncommon in infancy and in the former nephrocalcinosis has been reported in about one-third of the total number of cases. The combination of nephrocalcinosis and calculi is, however, uncommon and there was only this one case of infantile renal acidosis in this series. It seems likely that an abnormality in calcium excretion was responsible for the formation of the calculus in this case; in fact it seems rather surprising that there was only one such case and that stones are not seen more frequently in infants suffering from this condition.

Group 4. In 46 of the cases, it was not possible to ascribe definite causal factors. These cases have, therefore, been grouped together, and at first sight this appears to be a large proportion of the entire series. Although this is so, unknown causes would be responsible for a larger proportion of cases in a comparable adult series. Infection was present in 35 members of this group and in many of these was responsible for the presenting symptoms. Haematuria was frequent, but stones were only passed spontaneously in seven, or possibly eight, of the group. A most interesting feature of this group was the predominance of stones in the upper reaches of the urinary tract and in only one of the 46 cases were the calculi confined to the lower urinary tract. Another feature was the high proportion of dendritic, staghorn and multiple calculi (Fig. 5), and in eight of the cases the calculi were bilateral. The presenting symptoms were extremely variable and included pain, failure to thrive, haematuria and abnormalities of the urine. It is the site and size of these calculi which distinguish them rather than their symptomatology. Thirty-six of the cases in this group had renal calculi, unilateral or bilateral, alone or in combination with calculi in the lower parts of the urinary tract. Of these, 36, 33 had infected urine, and it seems likely that infection may have played an aetiological role. However, in only one case could it be proven that infection definitely preceded calculus formation. There were four cases with sterile urine so that infection presumably played no part in the pathogenesis of those. The findings on analysis and the sex incidence of the cases are further evidence against a primary infective theory to explain these stones. Nine cases did not quite conform to this pattern in that the stones were smaller, were ureteric in site and behaved in a manner reminiscent of adult stones. In eight of these the urine was sterile, surgery was required in six, in two of the remainder the stones were passed spontaneously and in the other surgery was considered unnecessary. It seems highly probable that the latter group are of no special paediatric significance, whereas the large

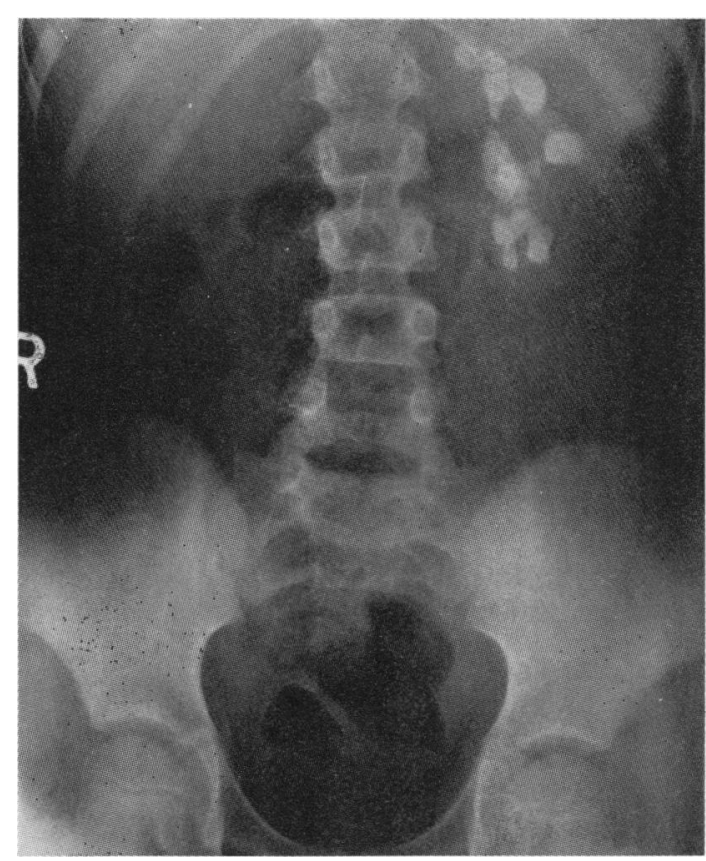

FIG. 5.-Renal calculi: plain radiograph of the abdomen of an 8 -year-old girl investigated for pyuria. Nephrectomy was subsequently performed. Albuminuria was known to have been present since the age of 3 years so that earlier investigation may have avoided the necessity for nephrectomy.

number of cases with large renal calculi are of much greater interest.

The last case in the 'unknown' group had a vesical calculus and infected urine; there was a mild degree of hydronephrosis in one kidney so that it is probable that this stone originated in the upper urinary tract. Metabolic studies were carried out on many of these 46 cases but there was never any evidence to incriminate hypercalcaemia, hypercalcuria or abnormal phosphate metabolism as causal factors.

\section{Age and Sex Incidence}

There were 52 boys and 33 girls in the series. This male predominance extended to all groups, but was most marked in the larger groups. The age at which symptoms first appeared is shown in Table 2, which indicates that although the cases were seen throughout the period of childhood, the peak of incidence occurred in patients under the age of 4 years. Altogether $63 \%$ of the patients fall into this age group. A similar trend was observed by Winkel Smith in 1944 who reported 71 patients, $46 \%$ of whom had symptoms before they were 4 years of age. The ratio of males to females in this series was 5 to 2 . It may be argued that the age at which the first symptoms appeared does not of 
necessity tell the age at which calculi were actually present. The symptoms may have preceded calculus formation or, on the other hand, the reverse could have occurred. The cases were particularly studied from this point of view, and there appeared little doubt that in most cases, if not all, the calculi had been present at least since the ages stated in Table 2.

TABLE 2

AGE INCIDENCE RELATED TO AGE OF FIRST SYMPTOMS

\begin{tabular}{c|r|r|r}
\hline \multirow{2}{*}{ Group } & \multicolumn{3}{|c|}{ Age of First Symptoms in Years } \\
\cline { 2 - 4 } & $0-4$ & $4-8$ & 8 and Older \\
\hline 1 & 16 & 4 & 5 \\
2 & 4 & 3 & 2 \\
3 & 4 & 1 & 4 \\
\hline
\end{tabular}

TABLE 3

AGE INCIDENCE RELATED TO AGE AT TIME OF DIAGNOSIS

\begin{tabular}{c|c|c|c}
\hline Group & $\begin{array}{c}\text { Aged } \\
\text { 0-4 Years }\end{array}$ & $\begin{array}{c}\text { Aged } \\
\text { 4-8 Years }\end{array}$ & $\begin{array}{c}\text { Aged } \\
\text { 8 Years and } \\
\text { and Older }\end{array}$ \\
\hline 1 & 11 & 6 & 8 \\
2 & 4 & 3 & 2 \\
3 & 25 & 3 & 10 \\
\hline
\end{tabular}

TABLE 4

ANALYSIS OF THE 54 CASES UNDER AGE 4 YEARS

\begin{tabular}{c|c}
\hline Age in Years & No. of Cases \\
\hline $0-1$ & 9 \\
$1-2$ & 16 \\
$2-3$ & 18 \\
$3-4$ & 11 \\
\hline
\end{tabular}

Although diagnostic delay did occur it was not frequent as is seen by comparing Tables 2 and 3 . Because such a high proportion of the patients were under the age of 4 years these younger cases were further analysed and the results are expressed in Table 4, which shows that in this series the maximum incidence was in the third year of life. Of the 18 cases which occurred during that year nine have been classified in the 'unknown' group.

\section{Bacteriology}

Infection was present in 60 cases (Table 5). The nature of the infecting organism can be seen in Table 6, and where more than one organism was present, the predominant one has been tabulated. Proteus was present in $60 \%$ of the infected cases.

\section{Site}

Table 7 shows the situation of the calculi in the various groups. Cases classified as 'multiple' include stones in both kidneys, stones in both ureters,
TABLE 5

INCIDENCE OF INFECTION

\begin{tabular}{l|c|c}
\multicolumn{1}{c|}{ Group } & Infection Present & Infection Absent \\
\hline 1. Congenital & 19 & 6 \\
Hydronephrosis & 2 & 3 \\
Mega-ureter & 8 & 2 \\
$\begin{array}{l}\text { Ectopia vesicae and } \\
\text { epispadias }\end{array}$ & 6 & 1 \\
Calyceal diverticulum & 1 & - \\
Crossed ectopia & 1 & - \\
Pyelon duplex & 1 & 8 \\
2. Metabolic & 1 & 0 \\
3. Other recognizable causes & 5 & 11 \\
4. Unknown & 35 & 25 \\
\hline \multicolumn{1}{c|}{ Total } & 60 & \\
\hline
\end{tabular}

TABLE 6

ORGANISM IN 60 INFECTED CASES

\begin{tabular}{l|c}
\hline \multicolumn{1}{c|}{ Organism } & No. of Cases \\
\hline Proteus & 36 \\
Esch. coli & 20 \\
Staph. aureus & 1 \\
Strep. faecalis & 2 \\
Strep. viridans & 1 \\
\hline
\end{tabular}

TABLE 7

SITE OF CALCULI IN THE VARIOUS CASES

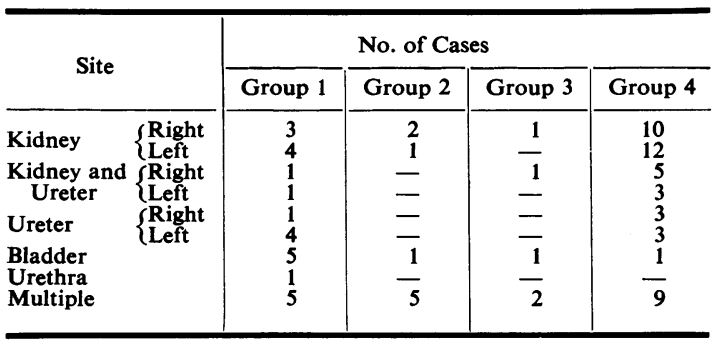

stones in both kidneys and one ureter, or both kidneys and both ureters, in one kidney and the contralateral ureter, or stones in both the upper and lower parts of the urinary tract.

Certain facts emerge from a study of Table 7. Thus in the 'unknown' group, $98 \%$ showed stones in the upper urinary tract alone or in combination with stone in the lower urinary tract. Conversely only nine cases in the entire series had stones in the bladder or urethra alone, and of these six were cases with ectopia vesicae or epispadias, one was metabolic in origin and one was secondary to a foreign body in the bladder. Only one vesical calculus was met with in the cases with unknown aetiology. It seems therefore that in this non-endemic series of stones, bladder calculi were virtually unknown unless there was some special reason for their production. This is in marked contrast to older reports and to presentday reports of endemic series of stones, the latter being well exemplified by reference to Brown and Brown's report (1941) from Syria on this problem. 


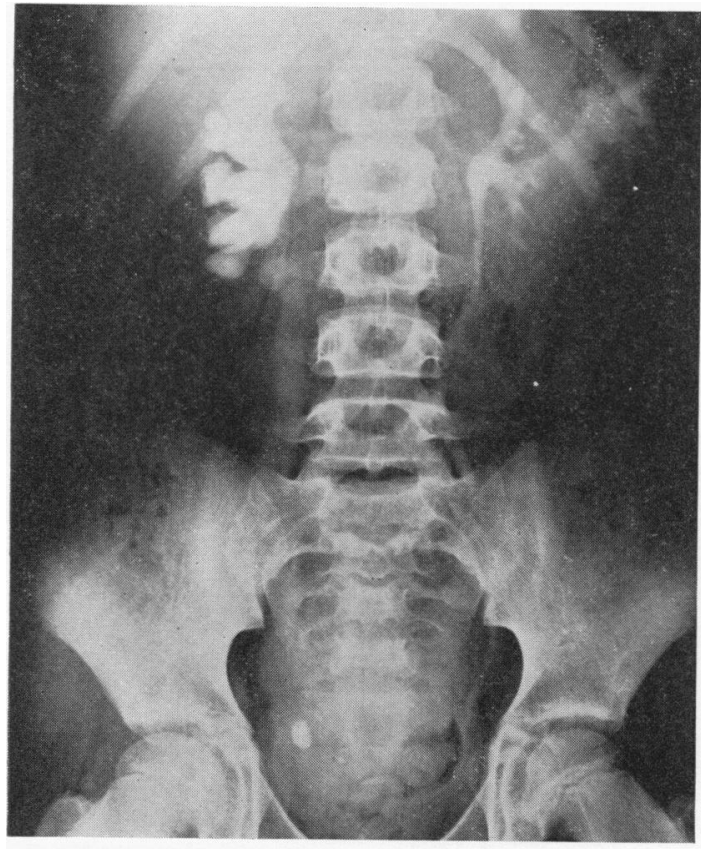

$6 \mathrm{a}$

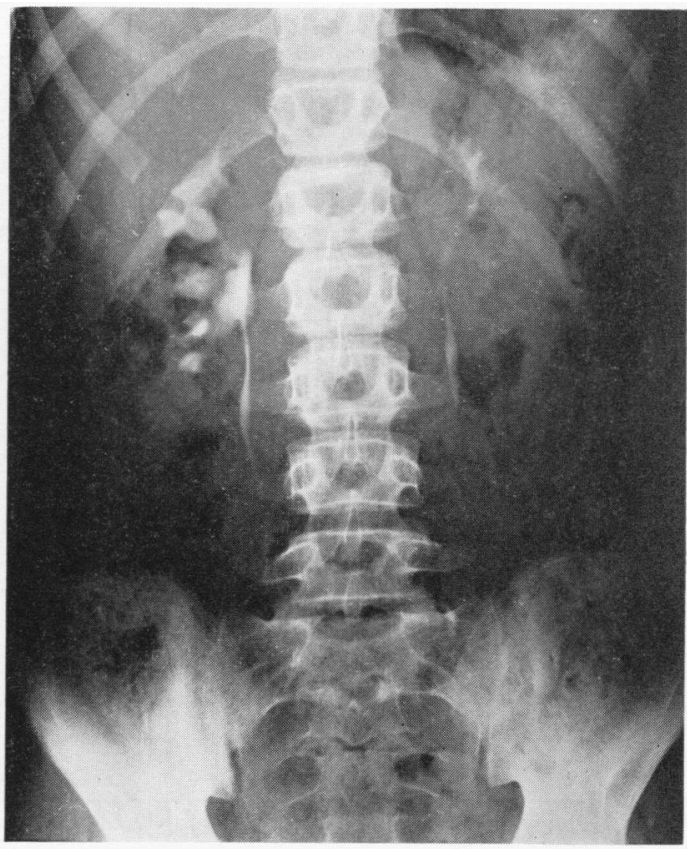

$6 \mathrm{~b}$

FIG. 6.-Ureteric calculus: intravenous pyelograms before and two years after removal of the calculus showing reversible ureteric dilatation. The patient was aged 9 years and had suffered trom attacks of abdominal pain and vomiting for 15 months.

\section{Radiological Findings}

All stones in this series were radio-opaque. Plain radiography was also used to follow the course of the disease after operation, and as will be seen later, is a useful adjunct to surgery. Intravenous pyelography was performed in many cases and was of considerable value in demonstrating anatomical abnormalities as well as giving some idea of renal function. One of the most important findings was dilatation of some part of the urinary tract, especially ureteric dilatation. In one group of cases the dilatation was primary and congenital, e.g., the cases of megaureters previously mentioned.

In a second group the dilatation was secondary to obstruction; ureteric stenosis was found in some cases. In others, stone in the ureter produced obstructive dilatation in the same way as this occurs under similar conditions in adults. Fig. 6 is an example of this type of problem; the figure shows serial radiography of a patient with a stone in the ureter. Originally it was thought that this represented a case of mega-ureter complicated by calculus formation, but ultimately it became apparent that there was no such underlying congenital abnormality.

In a third group, dilatation was seen below the calculi and in these it appeared that this was secondary (Fig. 7); the term 'ureterectasis' was employed to

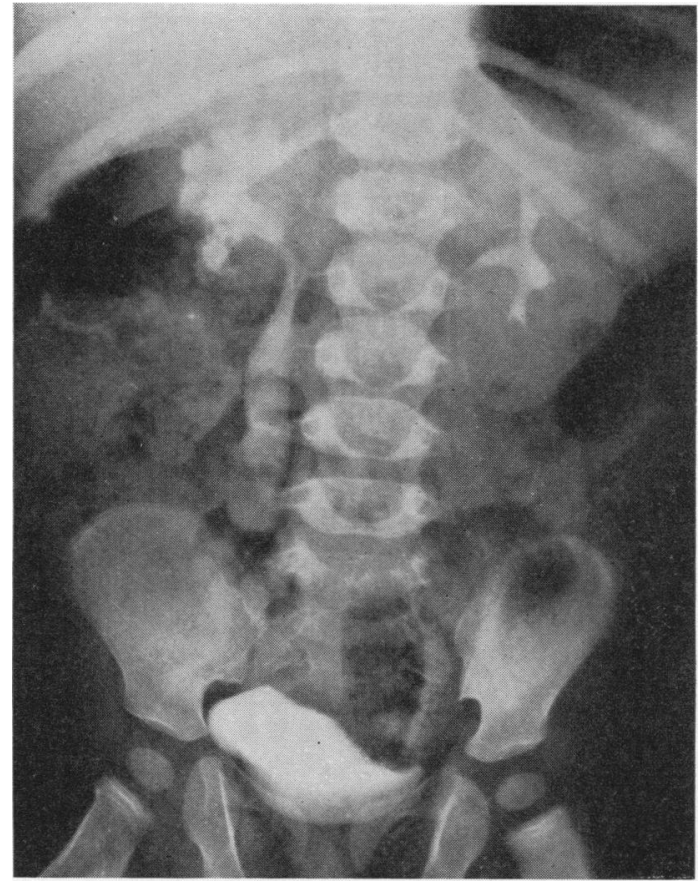

Fig. 7.-Renal calculus with ureterectasis: intravenous pyelogram in a baby, aged 20 months with persistent urinary tract infection. 
describe this finding. Considerable ureterectasis may be present and confusion as to the true diagnosis may readily result.

In some cases excretory pyelography was supplemented or replaced by retrograde pyelography. However, this latter procedure was only rarely necessary for purely diagnostic reasons.

\section{Analysis}

Calculi were analysed in 59 cases and the results are shown in Table 8 . In many, organic material

TABLE 8

CHEMICAL ANALYSIS OF THE CALCULI

\begin{tabular}{|c|c|c|c|c|}
\hline \multirow[b]{2}{*}{ Substance } & \multicolumn{4}{|c|}{ Group and No. of Cases } \\
\hline & 1 & 2 & 3 & 4 \\
\hline $\begin{array}{l}\text { Phosphate (including Ca. Mg. } \\
\quad \mathrm{NH}_{4} \text { and } \mathrm{CO}_{3} \text { ) } \\
\text { Phosphate-uric acid } \\
\text { Phosphate-urate } \\
\text { Phosphate-oxalate } \\
\text { Phosphate-oxalate-uric acid } \\
\quad \text { (or urate-) } \\
\text { Phosphate-oxalate-cystine } \\
\text { Oxalate } \\
\text { Oxalate-carbonate } \\
\text { Cystine } \\
\text { No record of analysis }\end{array}$ & $\begin{array}{r}13 \\
1 \\
1 \\
2 \\
- \\
- \\
- \\
\end{array}$ & $\begin{array}{l}- \\
\overline{1} \\
\frac{-}{2} \\
\frac{5}{1}\end{array}$ & $\begin{array}{l}\frac{4}{1} \\
- \\
- \\
- \\
-\end{array}$ & $\begin{array}{r}19 \\
2 \\
1 \\
2 \\
3 \\
1 \\
1 \\
17\end{array}$ \\
\hline
\end{tabular}

was found on analysis; however, it was not possible to correlate its presence or proportion with the presence or absence of infection. The most common finding was a phosphatic stone containing no trace of uric acid, urates or oxalates, and this occurred in 36 cases. The second most common finding was the pure cystine stone (five cases).

\section{Treatment}

One hundred and nine operations for removal of stone were performed in 77 of the cases, the discrepancy in the numbers being attributable to the cases with calculi in multiple sites and the cases with recurrence. The operative procedures (Table 9) consisted of simple removal of the stone alone (87

TABLE 9

109 OPERATIONS PERFORMED ON 77 CASES

\begin{tabular}{l|r|r|r|r|r}
\hline \multicolumn{1}{c|}{ Group } & 1 & 2 & 3 & 4 & Total \\
\hline $\begin{array}{llrl}\text { Pyelo-lithotomy } \\
\text { Nephro-lithotomy }\end{array}$ & 5 & 1 & - & 19 & 25 \\
Pyelo-nephro-lithotomy & - & 1 & 4 & 15 & 20 \\
Uretero-lithotomy & 6 & - & - & 7 & 7 \\
$\begin{array}{l}\text { Vesico-lithotomy } \\
\text { Urethro-lithotomy } \\
\text { Nephrectomy, nephro-ureterec- } \\
\text { tomy, hemi-nephrectomy }\end{array}$ & 4 & - & 2 & 5 & 22 \\
& 4 & 2 & - & 16 & 22 \\
\hline
\end{tabular}

operations) or removal of stone by excision of part of the renal tract ( 22 operations). Where indicated, corrective procedures on the urinary tract were carried out, e.g., pyelo-plasty, uretero-neo-cystostomy, lateral uretero-vesical anastomosis and bladder neck resection. Other operative procedures performed included drainage of a renal abscess. uretero-colostomy, pyelostomy and ureterotomy.

Of the eight cases which did not have any operative procedure, stones were passed spontaneously in five. Two of these were cases included in the 'unknown' group, the other three comprising one case of mega-ureter, one of ectopia vesicae and one case of familial oxaluria. The other three consisted of one patient awaiting operation, one with a small renal stone on whom surgery was not indicated, and one who died. This last was the only child in the series in whom death could be directly or largely attributed to the presence of calculi; he had multiple bilateral calculi and was admitted to hospital in a state of renal failure. The only other death in the series was a girl with a neurogenic disorder of the bladder who died as a result of the effects of back pressure and urinary infection.

Conservative methods of treatment included the use of the correct antibiotics and insistence on an adequate fluid intake. In the group with cystinuria, measures to alkalinize the urine were instituted and in one case with recumbency calculi 'aludrox' proved to be extremely efficacious.

\section{Discussion}

The diagnosis of urolithiasis in childhood should not present great difficulties and although the condition is now only seen infrequently, it is important that delay should not occur. Failure to recognize the condition may lead to chronic ill health and irreversible renal damage. Stone in the urinary tract is one cause of a diverse group of symptoms including those of urinary infection, haematuria and even physical retardation. Of these, the symptom which does merit particular stress is haematuria. Frank discoloration of the urine due to the presence of blood occurred in 35 cases, i.e., in over $40 \%$ of the series. In 26 , haematuria was the presenting complaint. In one, the initial diagnosis was 'angioma of the urethra' which must be one of the most infrequent conditions in childhood; in that patient nephrectomy was ultimately required and it appears almost certain that an earlier correct diagnosis might have prevented this necessity. Several cases were provisionally diagnosed as nephritis and several of these carried this label for rather long periods. Haematuria in an otherwise fit child calls for a full urological investigation and only in this way will diagnostic delays be avoided. As pointed out by Wyllie (1955) there are many causes of haematuria in 
childhood, but its total frequency is not great and therefore all cases should be carefully investigated.

Should the symptoms arouse any suspicion that the child may have stone somewhere in the urinary tract, investigation should lead to early confirmation, This investigation should proceed along three lines, namely, radiographic, metabolic and bacteriological. A plain film of the abdomen is very readily obtained and there seems no reason why this should not be routine in all children showing haematuria, except those obviously suffering from acute glomerulonephritis, and all cases of urinary infection in boys and chronic or recurrent urinary infection in girls. It might well be added that if Proteus be shown to be present added suspicion should perhaps be aroused. With regard to abdominal pain, wholesale radiographic examination is certainly not to be advocated, but if there is anything to suggest that the pain may have an organic basis, then a radiograph will rapidly diagnose or exclude urolithiasis as the basis for the symptoms. Because the condition is now rare, investigation of suspected cases will often lead the clinician to some alternative diagnosis, and in any case it is important to note that although plain radiography is of considerable value, excretory pyelography is the more important requirement in the final analysis.

Metabolic investigation will only prove valuable in a limited number of cases. However, the urine should be examined to diagnose or exclude the condition of cystinuria and if familial oxaluria is suspected, the daily oxalate excretion should be estimated.

Metabolic investigation is not complete until the removed stone has been analysed because further facts of value may then be discovered. Serum calcium studies should be carried out to avoid missing any condition causing a generalized upset in the calcium metabolism.

The conditions which enter the differential diagnosis are numerous, but it is possible to group them as follows: first, other conditions affecting the urinary tract, e.g., nephritis, infection without stone formation and neoplasms of the kidney; secondly, other conditions producing similar symptoms, e.g., abdominal colic of intestinal origin, febrile attacks of infection elsewhere in the body; and thirdly, conditions responsible for intra-abdominal calcification, e.g. nephrocalcinosis, tuberculous mesenteric adenitis.

The application of the label urolithiasis to the case is insufficient. To this must be added the underlying cause and the assessment of the entire urinary tract. In other words, the diagnostic requirements form a triad, namely, the diagnosis of urolithiasis, the diagnosis of the underlying lesion (if possible) and the anatomical state of the urinary tract and total renal function.

Treatment requires but little discussion. Few cases can be managed conservatively and once diagnosed, operation is of 'urgent convenience'. Pre-operatively complete assessment of the renal tract is essential in order to make the correct decision regarding the nature of the operative procedure. In some cases, simple removal of stone will suffice, in others an underlying anomaly may require simultaneous correction and in a third group excision of part of the renal tract will be needed to satisfy the therapeutic requirements. Except in this last instance operative radiography is of considerable value and when nephro-lithotomy or pyelo-lithotomy has been performed, the exposed kidney should be radiographed using a suitable technique. In this way any calculi remaining can be detected and removed immediately. Post operative measures should follow routine urological practice, namely choice of the correct antibiotic, alkalinization of urine in the 'metabolic' group and insistence on an adequate fluid intake. Prophylactic treatment is particularly relevant in the patients with inborn metabolic disorders, and to this end, when a 'metabolic' stone is discovered, the urine of other members of the family should be examined and the correct treatment instituted where necessary. Another aspect relevant to prophylaxis concerns recurrence, which can best be avoided by complete pre-operative investigation, and, at the time of operation by correction of any underlying congenital anomaly and removing all calculous material.

In some of the 'unknown' groups a history of acute (non-urinary) illness in the early months or years was obtainable and it is possible that some metabolic upset at such a time was responsible for the early calculus formation. In regard to this suggestion, phasic hypercalcuria is one possibility, temporary dehydration is another. Although this must remain hypothetical in these cases it is interesting to speculate about a disease which has so obviously changed its character during the last 100 years.

\section{Summary}

Urinary stone in childhood in this country has changed its character. No longer is the disease endemic; calculi are not found predominantly in the lower urinary passages, nor are they mostly composed of uric acid or urates.

Eighty-five cases seen at The Hospital for Sick Children during the past 20 years have been studied and their features exemplify these changes. The cases were classified into four clinical groups, in the largest of which aetiological factors were indefinite. 
Boys exceeded girls in the series (52 cases to 33) and the maximum incidence was during the third year of life. There was no significant discrepancy between the age at which symptoms first occurred and the age of diagnosis. In the cases with infected urine Proteus was the organism most commonly present. The significance of ureteric dilatation accompanying urolithiasis has been discussed and it was pointed out that the dilatation may be the cause (congenital mega-ureter) or the effect (ureteric obstruction due to calculus or ureterectasis) of stone.

There was a high proportion of phosphate stones, comprising $61 \%$ of the cases in which stones were analysed. Haematuria is a very frequent symptom and demands thorough investigation. In the series there was a definite relationship between age, sex and chemical analysis of the stones, and it is suggested that this relationship may be of some aetiologica significance.

It is a pleasure to express my thanks to Dr. D. I. Williams, genito-urinary surgeon to The Hospital for Sick Children, who originally suggested this study and whose advice and help were a constant stimulus. My thanks are also due to members of the consultant staff for permission to study their cases and to Mr. D. Martin for the preparation of the photographs. I also wish to express my indebtedness to the $\mathrm{X}$-ray and Records Departments for their help.

\section{REFERENCES}

Aponte, G. E., and Fetter, T. R. (1954). Amer. J. clin. Path., 24, 1363.

Brown, R. K., and Brown, E. C. (1941). Surgery, 9, 415.

Winkel Smith, C. C. (1944). Acta. chir. scand., 90, 1, 179.

Wyllie, G. G. (1955). Proc. roy. Soc. Med., 48, 1113. 